\title{
KEMANDIRIAN BELAJAR MAHASISWA MELALUI BLENDED LEARNING PADA MATA KULIAH METODE NUMERIK
}

\author{
Putri Fitriasari', ${ }^{1}$ Tanzimah ${ }^{2}$, Novita Sari $^{3}$ \\ 1,2,3 Universitas PGRI Palembang \\ putrifitriasari@univpgri-palembang.ac.id
}

\begin{abstract}
Abstrak
Penelitian ini bertujuan untuk mengetahui peningkatan kemandirian belajar mahasiswa (KBM) melalui blended learning. Metode penelitian yang digunakan adalah quasiexperimental dengan desain nonequivalent pre-test and post-test control-group. Subjek penelitian ini adalah mahasiswa program studi pendidikan matematika Universitas PGRI Palembang yang terdiri dari 54 mahasiswa yang terbagi ke dalam dua kelompok sampel, yaitu kelas eksperimen dan kelas kontrol. Kelas eksperimen diberikan perlakuan berupa blended learning, sedangkan kelas kontrol diberikan pembelajaran konvensional. Instrumen penelitian terdiri dari tes kemampuan awal mahasiswa (KAM) dan angket KBM. Data dianalisis secara deskriptif kuantitatif. Hasil penelitian menunjukkan bahwa peningkatan KBM yang mendapatkan perlakuan blended learning tidak lebih baik daripada mahasiswa yang mendapatkan pembelajaran konvensional.
\end{abstract}

Kata kunci: blended learning, kemandirian belajar.

\begin{abstract}
This study aims to know the improvement of student self-regulated learning (SRL) through blended learning. The method used is a quasi-experimental design with nonequivalent pre-test and post-test control-group. The subjects were students of mathematics education in the University of PGRI Palembang which consists of 54 students. They were divided into two groups of samples, namely the experimental class and control class. Experiment class got blended learning treatment, while control class got conventional learning. Research instrument consists of students' initial ability (SIA) test and KBM questionnaire. Data were analyzed quantitative descriptive. The results show that the improvement of SRL who get blended learning is not better than students who get conventional learning.
\end{abstract}

Keywords: blended learning, self-regulated learning.

\section{PENDAHULUAN}

Kemandirian belajar adalah sifat dan kemampuan yang dimiliki peserta didik untuk melakukan kegiatan belajar aktif yang didorong oleh motif untuk menguasai suatu kompetensi dan dibangun dengan bekal pengetahuan atau kompetensi yang telah dimiliki (Aini \& Taman, 2012). Selanjutnya, Darr dan Jonathan (2004) mengemukakan bahwa peserta didik yang memiliki kemandirian belajar adalah peserta didik yang secara aktif memaksimalkan kesempatan dan kemampuannya untuk belajar. Seorang peserta didik dikatakan mempunyai kemandirian belajar apabila ia mempunyai keinginan sendiri untuk belajar, menyelesaikan masalah, dan bertanggung jawab dalam menyelesaikan kewajibannya 
sebagai peserta didik. Namun kenyataannya kemandirian belajar mahasiswa sekarang ini sangatlah kurang. Hal ini didasarkan pada penelitian Nursa'ban (2013) yang menunjukkan bahwa pada siklus pertama rata-rata kemandirian belajar mahasiswa hanya sebesar 47 . Menurut Zumbrunn (2011) guru/dosen sebaiknya melaksanakan proses pembelajaran yang dapat memfasilitasi muridnya agar memiliki kemandirian belajar. Ini berarti bahwa dosen hendaknya mendesain suatu pembelajaran yang dapat membuat mahasiswa menjadi mandiri dalam belajar.

Salah satu pembelajaran yang dapat meningkatkan kemandirian belajar mahasiswa adalah blended learning. Hal ini sejalan dengan hasil penelitian Ismaniati (2015) yang menyimpulkan bahwa blended learning dapat meningkatkan kemandirian belajar mahasiswa dalam proses perkuliahan. Blended Learning adalah pembelajaran yang menggabungkan antara pembelajaran tatap muka (face to face) dan pembelajaran elektronik (e-learning) (Torrao, 2007). Whitelock dan Jelfs (2003) memberikan beberapa definisi mengenai blended learning, yaitu (1) kombinasi antara pembelajaran tradisional dengan pendekatan pembelajaran berbasis web, (2) kombinasi dari media dan tools dalam lingkungan e-learning, (3) kombinasi dari beberapa pendekatan pembelajaran, penggunaan teknologi pembelajaran. Dari beberapa definisi tersebut, dapat disimpulkan bahwa blended learning merupakan pembelajaran yang menggabungkan pembelajaran tatap muka (face to face) dan pembelajaran berbasis internet (e-learning). Melalui e-learning mahasiswa dilatih untuk belajar mandiri. Mahasiswa bisa memperkuat pengetahuannya dengan cara mencari sendiri pengetahuan yang mereka butuhkan melalui fasilitas internet dengan arahan dosen. Dengan memanfaatkan fasilitas internet, mahasiswa dapat mengakses sumber belajar dimana saja dan kapan saja. Walaupun demikian, pertemuan secara tatap muka juga diperlukan agar lebih mendekatkan dosen dengan mahasiswa. Selain itu, pemantauan terhadap respon mahasiswa juga dapat diamati dan diberikan umpan balik.

Berbagai penelitian telah dilakukan untuk mengkaji implementasi blended learning, antara lain penelitian yang dilakukan oleh Sari (2013) dan Sahin (2010). Sari (2013) menerapkan blended learning pada program studi pendidikan akuntasi. Hasil penelitiannya menyimpulkan bahwa strategi blended learning berhasil meningkatkan kemandirian belajar sebesar 72,8\%. Sedangkan, hasil penelitian Sahin (2010) menyatakan bahwa kemampuan belajar mahasiswa menjadi lebih baik setelah diterapkan blended learning.

Selain blended learning, penelitian tentang kemandirian belajar juga pernah dilakukan. Qohar (2010). Hasil penelitiannya menyatakan bahwa kemandirian belajar siswa melalui pembelajaran reciprocal teaching lebih baik daripada pembelajaran konvensional. 
Penelitian tentang blended learning dan kemandirian belajar juga sudah pernah dilakukan oleh Sutisna (2016), dari hasil penelitiannya juga menyimpulkan bahwa model pembelajaran blended learning efektif untuk meningkatkan kemandirian belajar peserta didik. Penelitian yang dilakukan Sutisna (2016) dilakukan pada tingkat sekolah menengah.

Berdasarkan hasil penelitian beberapa peneliti di atas, penelitian tentang kemandirian belajar melalui blended learning untuk tingkat pendidikan tinggi yang diterapkan pada program studi pendidikan matematika belum pernah dilakukan. Oleh karena itu, perlu dilakukan penelitian untuk melihat peningkatan kemandirian belajar mahasiswa program studi pendidikan matematika melalui blended learning.

Beberapa indikator untuk mengukur kemandirian belajar peserta didik yang diuraikan oleh Sumarmo (2004) yaitu: (1) inisiatif belajar; (2) mendiagnosa kebutuhan belajar; (3) menetapkan target atau tujuan belajar; (4) memonitor, mengatur dan mengontrol; (5) memandang kesulitan sebagai tantangan; (6) memanfaatkan dan mencari sumber yang relevan; (7) memilih dan menerapkan strategi belajar; (8) mengevaluasi proses dan hasil belajar; (9) self efficacy (konsep diri). Kesembilan indikator tersebut akan menjadi indikator kemandirian belajar dalam penelitian ini.

Tujuan penelitian ini adalah untuk mengetahui apakah peningkatan kemandirian belajar mahasiswa yang mendapatkan blended learning lebih baik daripada mahasiswa yang mendapatkan pembelajaran konvensional.

\section{METODE}

Penelitian ini merupakan penelitian eksperimen dengan tipe Quasi-Experimental. Desain eksperimen yang digunakan adalah desain kelompok kontrol pretes dan postes nonekuivalen atau nonequivalent pre-test and post-test control-group design. Secara singkat, desain eksperimen tersebut, dapat digambarkan sebagai berikut.

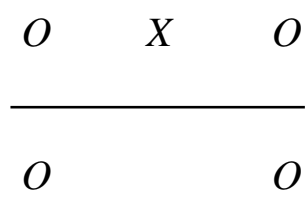

Keterangan:

$O \quad:$ pretes/postes KBM

X : blended learning

Subjek penelitian ini adalah mahasiswa semester genap tahun akademik 2016/2017 di Program studi Pendidikan Matematika Fakultas Keguruan dan Ilmu Pendidikan tingkat strata 1 pada Universitas PGRI Palembang. Subjek penelitian berjumlah 54 orang mahasiswa yang 
terdiri dari 2 kelas. Yaitu kelas eksperimen (30 orang) dan kelas kontrol (24 orang). Sebelum dilakukan penelitian kedua penelitian kedua kelas ini terlebih dahulu diuji kesetaraannya. Pemilihan kelas eksperimen dan kelas kontrol dilakukan secara acak. Instrumen angket kemandirian belajar menggunakan angket yang sudah valid dengan sedikit modifikasi.

Data hasil angket kemandirian belajar mahasiswa dianalisis dengan menggunakan statistik inferensial. Untuk mengetahui peningkatan kemandirian belajar mahasiswa dilakukan perhitungan gain ternormalisasi (g-gain), dengan interpretasi kategori n-gain menurut Hake (1999) seperti pada tabel 1 berikut ini.

Tabel 1. Kategori $n$-Gain ( $g$ )

\begin{tabular}{cc}
\hline n-Gain $(\boldsymbol{g})$ & Interpretasi \\
\hline$g>0,7$ & Tinggi \\
\hline $0,3<g \leq 0,7$ & Sedang \\
\hline$g \leq 0,3$ & Rendah \\
\hline
\end{tabular}

\section{HASIL DAN PEMBAHASAN}

\section{Hasil Penelitian}

\section{Deskripsi Data Kemampuan Awal Mahasiswa (KAM)}

Kemampuan awal mahasiswa (KAM) menggambarkan pengetahuan dan keterampilan mahasiswa tentang matematika sebelum dilibatkan sebagai subjek dalam penelitian. Tes KAM digunakan untuk mengetahui kesetaraan subjek penelitian, Untuk memperoleh gambaran kualitas KAM, data dianalisis secara deskriptif agar dapat diketahui rata-rata, simpangan baku, nilai minimum, dan nilai maksimum. Rangkuman hasil analisis deskriptif data KAM disajikan pada tabel 2. Selanjutnya dilakukan uji asumsi yaitu uji normalitas dan uji homogenitas varians data KAM yang hasilnya dapat dilihat pada tabel 3 dan tabel 4 .

Tabel 2. Statistik Deskriptif Data KAM

\begin{tabular}{cccccc}
\hline \multirow{2}{*}{ Kelas } & \multirow{2}{*}{$\mathbf{N}$} & \multicolumn{2}{c}{ Skor } & \multirow{2}{*}{ Rerata } & $\begin{array}{c}\text { Simpangan } \\
\text { Baku }\end{array}$ \\
\cline { 3 - 4 } & & Min & Maks & & 3,27 \\
\hline Kelas A & 24 & 7 & 20 & 12,79 & 3,47 \\
\hline Kelas B & 30 & 7 & 21 & 13,10 & 3,47 \\
\hline Skor maksimal ideal $=30$ & & &
\end{tabular}

Tabel 3. Uji Normalitas Data KAM

\begin{tabular}{cccccl}
\hline \multicolumn{1}{c}{ Kelas } & N & K-S & Sig. & Ho $_{0}$ & Kesimpulan \\
\hline Kelas A & 24 & 0,137 & 0,200 & Diterima & Normal \\
\hline Kelas B & 30 & 0,124 & 0,200 & Diterima & Normal \\
\hline
\end{tabular}

Tabel 4. Uji Homogenitas Data KAM

\begin{tabular}{cccccc}
\hline Kelas & $\mathbf{N}$ & $\mathbf{F}$ & Sig. & $\mathbf{H}_{0}$ & Kesimpulan \\
\hline Kelas A & 24 & \multirow{2}{*}{0,185} & \multirow{2}{*}{0,669} & Diterima & Homogen \\
\hline Kelas B & 30 & & & & \\
\hline
\end{tabular}


Berdasarkan Tabel 3, terlihat bahwa nilai probabilitas (sig.) kelas A dan kelas B sama besar yaitu 0,200 dan lebih besar dari taraf signifikansi 0,05 , sehingga $\mathrm{H}_{0}$ diterima. Hal ini berarti data tersebut berdistribusi normal. Selanjutnya, Tabel 4 juga menunjukkan nilai probabilitasnya lebih besar dari taraf signifikansi 0,05 yaitu 0,669 , sehingga $\mathrm{H}_{0}$ diterima. Dengan demikian, data tersebut berdistribusi normal dan homogen.

Setelah diketahui bahwa data tersebut berdistribusi normal dan homogen, maka untuk mengetahui kesetaraan data dari dua kelas tersebut dilakukan uji rerata menggunakan statistik parametrik uji t. Rangkuman hasil uji $t$ disajikan pada Tabel 5.

Tabel 5. Uji Perbedaan Rerata Data KAM

\begin{tabular}{cccc}
\hline Kelas & Sig. & $\mathbf{H}_{\mathbf{0}}$ & Kesimpulan \\
\cline { 1 - 1 } Kelas A & 0,741 & Diterima & $\begin{array}{c}\text { Tidak ada } \\
\text { perbedaan }\end{array}$ \\
\cline { 1 - 3 } Kelas B & & &
\end{tabular}

Dari Tabel 5, dapat dilihat bahwa nilai probabilitasnya lebih besar dari taraf signifikasi 0,05 sehingga $\mathrm{H}_{0}$ diterima. Ini berarti tidak terdapat perbedaan yang signifikan pada rerata data KAM kelas sampel penelitian. Hasil ini memberikan kesimpulan bahwa mahasiswa pada kedua kelas sampel memiliki KAM yang setara/sama. Selanjutnya, pemilihan secara acak kelas A sebagai kelas kontrol dan kelas B sebagai kelas eksperimen.

\section{Deskripsi Data Peningkatan Kemandirian Belajar Mahasiswa (KBM)}

Data peningkatan kemandirian belajar mahasiswa didapatkan dari skor peningkatan (ngain) kemandirian belajar mahasiswa. Statistik deskriptifnya dapat dilihat pada tabel 6 .

Tabel 6. Statistik Deskriptif Data Kemandirian Belajar Mahasiswa

\begin{tabular}{|c|c|c|c|c|c|c|c|c|c|}
\hline \multicolumn{5}{|c|}{ BL } & \multicolumn{5}{|c|}{ PK } \\
\hline$N$ & Stat. & Pretes & Postes & $\langle\mathrm{g}\rangle$ & $\mathbf{N}$ & Stat. & Pretes & Postes & $\langle\mathrm{g}\rangle$ \\
\hline \multirow{2}{*}{30} & $\bar{x}$ & 75,93 & 81,08 & 0,21 & \multirow[b]{2}{*}{14} & $\bar{x}$ & 79,02 & 81,09 & 0,11 \\
\hline & $s$ & 2,82 & 6,55 & 0,26 & & $s$ & 4,89 & 5,83 & 0,18 \\
\hline
\end{tabular}

Tabel 6 menunjukkan secara keseluruhan mahasiswa yang mendapatkan blended learning mengalami peningkatan KBM yang lebih besar daripada mahasiswa yang mendapatkan pembelajaran konvensional. Untuk lebih jelas dapat dilihat pada gambar 1. 


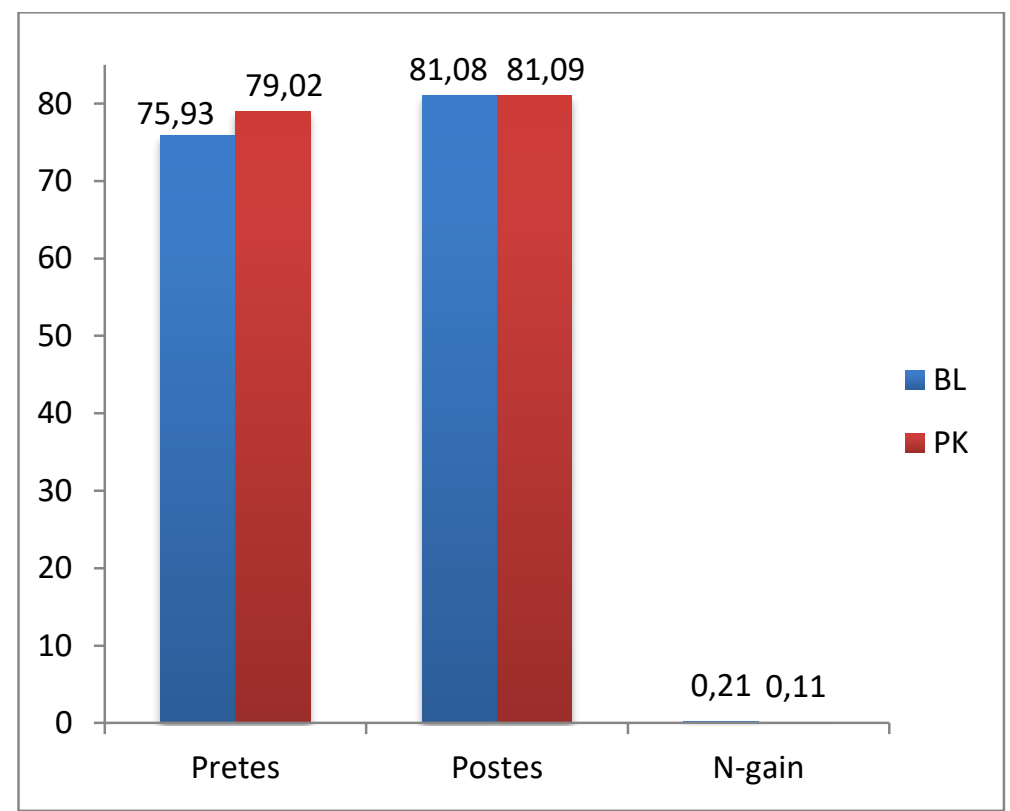

Gambar 1. Grafik pretes, postes, dan n-gain

Untuk mengetahui apakah peningkatan kemandirian belajar mahasiswa yang mendapat BL lebih baik daripada mahasiswa yang mendapatkan PK, diajukan hipotesis sebagai berikut: mahasiswa yang mendapat BL memperoleh peningkatan kemandirian belajar lebih baik daripada mahasiswa yang mendapatkan PK. Pengujian hipotesis tersebut diawali dengan melakukan uji prasyarat terlebih dahulu untuk menentukan uji apa yang akan digunakan. Uji prasyarat yang digunakan yaitu uji normalitas dan uji homogenitas. Hasil uji normalitas dapat dilihat pada Tabel 7 berikut ini.

Tabel 7. Uji Normalitas Data Peningkatan KBM

\begin{tabular}{ccccc}
\hline Pembelajaran & $\boldsymbol{N}$ & K-S & Sig. & Kesimpulan \\
\hline BL & 30 & 0,199 & 0,004 & Tidak Normal \\
\hline PK & 24 & 0,200 & 0,014 & Tidak Normal \\
\hline
\end{tabular}

Berdasarkan Tabel 7 diketahui bahwa data peningkatan kemandirian belajar mahasiswa tidak berdistribusi normal. Karena data yang didapat tidak berdistribusi normal, maka uji homogenitas tidak perlu dilakukan. Pengujian hipotesis dilanjutkan dengan uji Mann Whitney. Hasil Uji Mann Whitney dapat dilihat pada tabel 8.

Tabel 8. Uji Perbedaan Rerata Data Peningkatan KBM

\begin{tabular}{cccc}
\hline Pembelajaran & $\begin{array}{c}\text { Mann- } \\
\text { Whitney } \mathbf{U}\end{array}$ & Sig. & $\mathbf{H}_{\mathbf{0}}$ \\
\hline BL & $-1,675$ & 0,094 & Diterima \\
\hline PK & & & \\
\hline
\end{tabular}


Dari Tabel 8 terlihat bahwa nilai signifikansi statistik uji Mann Whitney sebesar 0,094. Nilai signifikansi ini lebih besar dari taraf signifikansi 0,05 sehingga hipotesis nol diterima. Ini berarti tidak terdapat perbedaan yang signifikan antara rerata data peningkatan kemandirian belajar mahasiswa yang mendapatkan blended learning dengan yang mendapatkan pembelajaran konvensional.

\section{Pembahasan}

Hasil penelitian ini menunjukkan bahwa uji perbedaan rerata peningkatan KBM pada Tabel 8 mempunyai nilai signifikan sebesar 0,094, dan nilai signifikan ini lebih besar dari taraf signifikansi 0,05. Sehingga hipotesis nol diterima. Ini berarti tidak terdapat perbedaan yang signifikan antara rerata data peningkatan KBM mahasiswa yang mendapatkan blended learning dengan yang mendapatkan pembelajaran konvensional pada taraf signifikansi $\alpha=$ 0,05. Dengan demikian dapat disimpulkan bahwa secara keseluruhan peningkatan kemandirian belajar mahasiswa yang mendapatkan blended learning tidak lebih baik daripada mahasiswa yang mendapatkan pembelajaran konvensional.

Menurut Izzudin (2012) blended learning adalah pembelajaran yang menggabungkan pembelajaran secara tatap muka (face to face learning) dan secara virtual (e-learning). Pernyataan ini sejalan dengan temuan penelitian Sari (2013) yang menyimpulkan bahwa strategi blended learning berhasil meningkatkan kemandirian belajar sebesar $72,8 \%$. Selain itu Sutisna (2016) dari hasil penelitiannya juga menyimpulkan bahwa model pembelajaran blended learning efektif untuk meningkatkan kemandirian belajar peserta didik. Jika kita lihat beberapa penelitian di atas, dapat disimpulkan bahwa blended learning mampu meningkatkan kemandirian belajar mahasiswa karena e-learning merupakan perpanjangan dari ruang kelas yang bisa diakses oleh mahasiswa dimana saja. Pada penenlitian ini, peningkatan KBM yang mendapatkan BL tidak lebih baik daripada mahasiswa yang mendapatkan PK. Akan tetapi jika dilihat peningkatan rerata kelas yang mendapatkan BL pada tabel 6 lebih tinggi nilainya daripada rerata kelas yang mendapatkan PK, yaitu sebesar 5,15 dan 2,07. Selain itu, dari nilai n-gain juga terlihat bahwa kelas yang mendapatkan perlakuan BL lebih tinggi nilainya dari pada kelas PK, yaitu sebesar 0,21 dan 0,11. Ini membuktikan bahwa blended learning berpotensi untuk meningkatkan kemandirian belajar mahasiswa.

\section{SIMPULAN}

Berdasarkan rumusan masalah, hasil penelitian, dan pembahasan yang telah dikemukakan sebelumnya, diperoleh simpulan bahwa peningkatan kemandirian belajar 
mahasiswa yang mendapatkan blended learning tidak lebih baik daripada mahasiswa yang mendapatkan pembelajaran konvensional. Akan tetapi, blended learning berpotensi untuk meningkatkan kemandirian belajar mahasiswa.

\section{UCAPAN TERIMA KASIH}

Peneliti mengucapkan terima kasih kepada Menteri Riset, Teknologi, dan Pendidikan Tinggi yang telah memberikan sponsor penelitian ini melalui Hibah Penelitian Dosen Pemula untuk pendanaan tahun 2017 dan Universitas PGRI Palembang yang telah membantu terlaksananya penelitian ini.

\section{DAFTAR PUSTAKA}

Aini, P. N., \& Taman, A. (2012). Pengaruh Kemandirian Belajar dan Lingkungan Belajar Siswa terhadap Pretasi Belajar Akuntansi Siswa Kelas XI IPS SMA Negeri 1 Sewon Bantul Tahun Ajaran 2010/2011. Jurnal Pendidikan Akuntansi Indonesia, X (1): 48-65.

Ismaniati. (2015). Model Blended Learning untuk Meningkatkan Kemandirian Belajar dan Daya Tarik dalam Perkuliahan. Jurnal Penelitian Ilmu Pendidikan, 8(2): 19-27.

Nursa'ban, M. (2013). Peningkatan Sikap Tanggung Jawab dan Kemandirian Belajar Mahasiswa melalui Metode Tutorial di Jurusan Pendidikan Geografi. Cakrawala Pendidikan, XXXII(3): 432-443.

Qohar, A. (2010). Mengembangkan Kemampuan Pemahaman, Koneksi, dan Komunikasi Matematis serta kemandirian Belajar Matematika Siswa SMP melalui Reciprocal Teaching. Disertasi tidak dipublikasikan. Universitas Pendidikan Indonesia. Bandung.

R.R. Hake, (1999). Analyzing Change/Gain Scores (online), (http://www.physics.indiana.edu/ sdi/AnalyzingChange-Gain.pdf) diakses 20 Maret 2017.

Sahin, M. (2010). Blended Learning in Vocational Education: An Experiment Study. International Journal of Vocational and Technical Education, 2(6): 95-101.

Sari, A. R. (2013). Strategi Blended Learning untuk Peningkatan Kemandirian Belajar dan Kemampuan Critical Thinking Mahasiswa di Era Digital. Jurnal Pendidikan Akuntansi Indonesia, XI(2): 32-43.

Sutisna, A. (2016). Pengembangan Model Pembelajaran Blended Learning pada Pendidikan Kesetaraan Program Paket C dalam Meningkatkaan Kemandirian Belajar. Jurnal Teknologi Pendidikan, 18(3): 156-168.

Syarif, I. ( 2012). Pengaruh penerapan model blended learning terhadap motivasi dan prestasi belajar siswa SMK. Jurnal Pendidikan Vokasi, 2(2): 234-249.

Torrao, S. (2007). Blended Learning: Research Report \& Examples of Best Practices. Estonia. University of Tartu.

Whitelock, D. \& Jelfs, A. (2003): Editorial. Special Issue on Blended Learning Journal of Educational Media. Journal of Education Media, 28(2): 99-100.

Zumbrunn, et al. (2011). Encouraging Self-Regulated Learning in the Zlassroom: A Review of the Literature. Metropolitan Educational Research Consortium (MERC), Virginia Commonwealth University. 